GENERAL ARTICLE

\title{
Globalization from within: Interplay of the local and the global in Sri Lanka
}

\author{
Nalani M Hennayake \\ Department of Geography, Faculty of Arts, University of Peradeniya, Peradeniya
}

\begin{abstract}
Globalization continues as an inescapable process in many of the third world societies. Both popular and academic accounts focus on a bird's eye view of this process, with a privileged emphasis on the economic aspect. As a result, the geographies of globalization are disregarded, leading to subtle and complex implications especially upon third world postcolonial societies (where globalization is taking a new turn affecting their cultural identity) unnoticed. The author argues that, the attempts within Human Geography to redress this situation, has largely been limited to a theoretical discourse on how to articulate the global-local relations and further points out that most of the empirical studies available on Europe and America simply examine the economic aspects of globalization or urban changes. This study attempts to explain how globalization unfolds differently in different places, unravelling the intricacies of globalization from within Sri Lanka. It points out that besides local globalization, global localization takes place. Each of the four empirical examples used in the article demonstrates a different set of global-local relations. The study concludes that since the global is causally more powerful than the local, the subtle relations between the global and the local may lead to the displacement of local culture on the one hand, while inflicting differential impacts on various social groups.
\end{abstract}

\section{INTRODUCTION}

The objective of this study is to explain how globalization in specific places occurs as an interplay of "global" and "local" by the culture becoming instrumental in this process. Although the expanding processes and structures of globalization are, by and large, global in scale, the actual impact and its varying manifestations occur in specific places. It could therefore be argued that, to grasp the dynamics and subtleties of the process of globalization, it is essential to understand not only global dynamics but also examine how globalization is received, adopted, internalized and reacted to in different places. ${ }^{1}$ Examining the impact of globalization from a distant place (relative to U.S.A. or Western Europe) such as Sri Lanka will enrich the understanding of its geographical distinctiveness. However, in this endeavor, instead of dwelling on either philosophical or moral arguments, globalization is taken as a fact of reality that globalization continues regardless of the so called knowledge-related arguments in the academic discourse.

The paper is organized into six sections. Following the introduction, the section 2 explains the working definitions of the two key terms used - local and global. In the section 3, presenting the globalization debate, this study is placed in the broader context of the globalization debate, highlighting the features of the general literature and in the section 4, the relations between the global and the local are articulated within the discipline of geography. These two sections are dealt with rather briefly to focus on the empirical section. The section 5 is divided into two parts: the first provides a general introduction to globalization in Sri Lanka and the second section provides the empirical narratives, illustrating the local-global relations in Sri Lanka. In the section 6 , the implications emerging from these relations are discussed with theoretical reflections upon our thinking and analysis. 


\section{DEFINING THE LOCAL AND THE GLOBAL}

Generally, geographers as well as most other Social Scientists associate "global" with the whole world at the international level (hence "global scale"), while the local is viewed as encompassing both the national and intra national. These are the implicit geographical boundaries of global and local, both in terms of scale and space. However, what is imperative is, as Allen and Massey (1995) point out, "to grasp both the wider, global context of which we are a part of and what it is that makes us distinctively local". ${ }^{2}$ Thus, to comprehend the geographies of globalization, one needs to understand it from different scales, not simply from the global only (Dodds, 1999; Kelly, 1999). However, scale should not be considered as "a container for social processes or simply a hierarchical division of space" ... but "rather as a site of interaction between social forces operating across scales" (Kelly, 1999). Once the scales are considered as "sites of interaction," global spaces can exist in local settings and local spaces in global settings. If one employs the notion of a spatial hierarchy of scales of globalization, Sri Lanka will be placed at national, while what is within Sri Lanka will automatically be local. ${ }^{3}$ If so, national and local scales will invariably contain "global" characteristics such as intensity of trade, foreign direct investment, network communication etc.

It appears that the spatial scales of global and local are less useful in exploring how globalization occurs in actual places, especially because societies such as Sri Lanka make the global- local distinction more in social/ cultural terms than in a strictly scalar sense. Thus, phenomena constituted of or attached to global capital, technology, know-how and social behavior are identified as global. The local is identified as constitutive of elements of cultural distinctiveness and it entails a notion of indigenousness. These are very general meanings that can be given to the terms, global and local. In fact, it is difficult to compartmentalize the two categories strictly, because what can actually be seen are different permutations of the local and global. Since there is no particular terminology for such permutations, the terms global and local tend to be used for either analytical convenience or conceptual clarification. ${ }^{4}$ For example, in the Sri Lankan context "McDonalds" is global regardless of how it has been localized, while the Ayurveda health system is local regardless of how it has been globalized. Whether terms such as "glocalization" as proposed by Swyngdelouw (1992) allow such permutations to be comprehended is yet to be seen.

\section{THE GLOBALIZATION DEBATE: AN OVERVIEW}

The literature on globalization accumulated within the last decade is incredibly vast and spreads across disciplines, contributing to its variegated nature. However, two characteristic features of this literature must be highlighted. Firstly, the majority of these literature articulates theoretical aspects of globalization and as a result a large number of those are overviews. (Mittelman and Othman, 2001; Ohmae, 1990; Robertson, 2003; Scholte, 2000; Scott, 1997; Schaeffer, 2003; Schirato and Webb, 2003; Short, 2001; Sklair, 2002: Waters, 1995). A few are empirical reviews. Secondly, those studies explain globalization predominantly as an economic process, emphasizing the increasing power of the multinational corporations and expansion of financial markets together with the theme of the waning power of the nation-state (Allen, 1995; Dicken, 1998; Taylor and Thrift, 1986; Amin and Thrift, 1994; Ohmae, 1990; Kortan, 1995). A few have focused on the 'global culture' argument (Smith, 1990; Appadurai, 1990, 1996; Robertson, 1992). ${ }^{5} \quad$ It is thus reasonable to state that in most of the literature the view of globalization is a "bird's eye view", as an all-encompassing process privileging the global scale in analysis, (Fagan, 1997; Kelly, 1999) and economic in focus, to the neglect of its dynamics in specific places. ${ }^{6}$ (This will be referred to as "globalist approach" in this paper). Voisey and O'riordan (2001) confirming this state that, "there is a fracture between the empirical and theoretical sides of the debate on globalization. Indeed, the literature on globalization does not appear to provide a good basis for empirical analysis of societal change since there is no one model that is possible".

This globalist approach has had two drawbacks on making sense of globalization, which is in fact directly related to the objective of this paper. Firstly, it is taken for granted that globalization takes place globally, thus overlooking a typical yet important geographical question-that is, where exactly does globalization occur? The literature on globalization makes insufficient reference to specific places and most of such reference is related only to economic aspects of globalization. While one may agree that there is a process of globalization that is global in extent, this study argues that the actual workings of globalization are connected to real places shaping and reshaping the lives of people, knowingly or unknowingly. Secondly, the overwhelming economic emphasis has shrouded the significance of its cultural realm. Discussion 
of culture in relation to globalization is largely couched in the language of cultural homogenization or hybridization resulting from the rapid expansion of communication and technology (Appadurai, 1990, 1996; Featherstone, 1990; Hannerz, 1990) or as a consequence of global capitalism (Harvey, 1989; Street, 1997). Mittleman (2001), recognizing this problem in the globalization debate suggests that we should "employ a holistic approach and turn to cultural political economy". Two studies in Mittleman's “Capturing Globalization”, Osman's (2001) study on indigenous people in Sarawak and Mandal's (2000) study on the impact of the English language on Malaysia, demonstrates that a more comprehensive approach that deals with both the economic and cultural simultaneously is needed to understand the dynamics of globalization. The present study, although it may not fall neatly into the 'cultural political economy' in a classical sense, attempts to explore the cultural dynamics entwined with the economic changes.

\section{'GLOBAL AND LOCAL RELATIONS' IN THE GLOBALIZATION DEBATE}

The perception of globalization as a process that involves an interrelationship between global and local must in itself be considered as a progressive step towards addressing the drawbacks in the globalist approach. This approach is well expressed through the terminology itself - "local globe" O'riordan (2001), "(g)lobality, Glocality, and "glocality" (Voisey and O'riordan, 2001), "from global village to local globe" (Rosenau, 2003) and "glocalization" (Swyngedouw, 1992). Particularly within Human Geography, the need for a more contextual/dialectical approach to space and place, recognizing the significance of both global and local, is well expressed by Allen and Massey (1995). Amin and Thrift (1997) highlight the "territorializing tendencies of globalization" recognizing the interdependencies between global and local, but warn against waging war between "global flows" and "local fixities". Recently, this interest has extended to discussions on simultaneity of scales (Swyngedow, 1997; Kelly, 1999) in human experience, expressing the need to transcend the hierarchical privileging of certain scales. Thus, the need to articulate the relationship between the global and local in a non-opposing, dialectical manner, without privileging any one of them, while at the same time highlighting their interdependencies, is accepted and theoretically well-argued both in relation to the debate of globalization and otherwise, by geographers (Amin and Thrift, 1997; Dicken, Peck and Tickell, 1997; Cox ,1997; Koffman and Young, 1996; Swyngedow, 1997; Kelly,
1999) as well as non-geographers (O'riordan (ed), 2001; Rosenau, 2003). Here, the tensions between global and local both in terms of social and geographical scale are imaginatively captured in Rosenau's notion of "distant proximities." Rosenau notes that, "Distant proximities are not simple interrelationships readily discernible and understood... Distant proximities encompass the tensions between the global and local.... All these tensions are marked by numerous variants; they take different forms in different parts of the world." (2003). This is a concept that can be used by the geographers to unravel the globallocal tensions. The empirical instances that are discussed in this paper can actually be considered as 'sites of interaction' where 'distant proximities' are negotiated.

Undoubtedly, geographers have theoretically argued their case for the dialectic of global and local. However, Dicken, Peck and Tickell (1997), arguing for a more "nuanced and iterative analysis which conceptualizes the global within the local and local within the global", point out that "the debate of globalization has been profoundly ageographical". Geographers have not adequately ventured into exploring how this interplay actually occurs in different places in the world. Geographical reference has been sporadic and limited to descriptive, empirical verifications of global tendencies and "national" has presumed recognition as local scale in most of these studies (Amin and Thrift, 1997). This geographical reference, whenever made, has also been either on East Asia, concentrating on Japan and China (Park, 2003) or case studies from Europe or U.S.A, (Herod, 1997; Leyshon and Thrift, 1993; Peck and Tickell, 1995 Amin, and Thrift, 1994) with the exception of Agnew and Grant (1997) and Barret et.al, (1999) on Africa. Not much attention has been paid to third world, postcolonial societies where globalization is taking a new turn affecting their cultural identity. Therefore, it could be argued that the theoretical debates are not adequately informed by the variety and the specificity of particular articulations of the global and local.

Probably being prejudiced by the globalist approach, empirical studies have largely been confined to economic, focusing on labor relations, market expansion and capital formation (Barret et.al, 1999; Ettlinger, 1999; Peck and Tickell, 1994; Herod, 1997), while some have concentrated on urban changes (Cox, 1993; Yeoh, 1999). This could actually be attributed to the fact that it was the economic geographers who were mostly involved in the debate, while cultural geographers have generally kept away from this theme. In fact, Leyshon (1997) points out that "globalization only really seemed to be of interest 
to those who had an attachment to the issue through an interest in the geography of multinational corporations (Taylor and Thrift, 1986), or those who were investigating the geography of producer and financial services, which during the 1980s began 'to go global' at a rapid pace". Further, Leyshon cites Roberts (Roberts, 1992 cited in Leyshon, 1997), that economic geographers have "tended to produce works that are focused empirically on some aspect of the economic (rather than the social and cultural) geographies of globalization.” Thus, generally, empirical studies exploring social

Figure 1 : Globalization

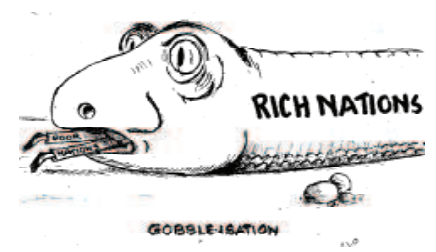

Source: Sunday Island (March 31, 2000), Lake House, Colombo, Sri Lanka and cultural dynamics are rare within the literature. Nijman (1999) and Skelton (1996) attempt to move away from this economic determinism by focusing on the cultural dynamics. Nijman explores how cultural globalization affects urban identities through changing images of localities in Amsterdam. Skelton's (1996) study on the Caribbean which begins with the question, "What happens to local culture in the face of globalization? Can they resist global processes?" is an exception to this both in focus and approach. ${ }^{7}$ In this wider context, examples from Sri Lanka presented here will make clear to the geographers who are interested in globalization, the need to look deeply into places with a focus not only on the economic but also the social and cultural in order to understand the dynamics of globallocal relations within the process of globalization.

\section{GLOBALIZATION IN SRI LANKA: SOME INTRODUCTORY NOTES}

The objective of this section is to position the reader in the general context of globalization in Sri Lanka, before examining specific examples. In an abstract sense, globalization is conceptualized as a process that involves a dramatic increase in the relationships and interconnections of different degrees among various places and people in all spheres of life at different scales. Empirically, it appears that the nature and the intensity of the increasing interrelationships and interconnections with their unpredictable implications vary geographically, not only among, but also within national societies. Therefore, even within a small country such as Sri Lanka, globalization derives different interpretations.
The conservative liberals allying with the globalist, view globalization as a progressive and unavoidable process, while the critics argue that it is nothing but a continuation of colonialism and imperialism, as aptly depicted by a Sri Lankan cartoonist ( Figure 1). Regardless of these controversies, it is a reality that neo-liberal economic changes introduced in 1977 made the modalities of global capitalism gradually felt by the larger society, bringing "globalization" into effect. While the economy has become more outward oriented, emphasizing the significance of trade and investment, the country at large is transformed into a society steeped in a consumerist culture, where credit cards, cell phones, computers, internet, blue jeans and fast food have become symbols of globalization and signs of opulence. This has created yet another challenge for the rural, poor people (locals) - not only to fight their relative poverty, but also to struggle to be globalized (through access to credit, operational English knowledge and computer literacy) avoiding further obstacles to their path towards economic prosperity. ${ }^{8}$

This challenge is taken up by Sri Lanka, which prides itself on leading into the age of globalization. The best example of this is the state sponsored obsession of "computerizing" society in order to access the global world, thus making a transition from the "developmentalist state" to the "globalist state." Although Cerny (1997, 2003) recognizes a threat to the legitimacy of state as it becomes a "competition state with globalization," the Sri Lankan state on the contrary derives its legitimacy by catering to globalization.

The global cultural universe created around the television adds yet another dimension to globalization in Sri Lanka. When sitting in front of the television, one is willingly or unwillingly placed within the 'global' cultural universe. This is seen simultaneously, both as an 'expansion of horizons' and a 'shrinking of the local culture'. Children watch Sesame Street to Mortal Combat, Batman to Night Rider. Soap Operas such as "Santa Barbara" take much time on the afternoon television of certain channels while holidays are packed with Hindi movies! All the eight television channels telecast non-Sri Lankan programs at particular times on certain days. Individual experience in this global cultural universe varies very much; it does not fit neatly into either the global, national or local scales, on the one hand, or the diverse social classes on the other.

What has been outlined here is only a sketchy, but general picture of globalization; the following examples will reveal the actual workings and subtleties involved in the globalization process. 


\section{GLOBAL AND LOCAL RELATIONS IN SRI LANKA: EMPIRICAL EXAMPLES}

The Globalization process in Sri Lanka reveals the simultaneous trend of the "global being localized" and the "local being globalized". This could be perceived best as a nexus of relationships and interconnections between global and local producing "in-between tendencies" rather than as two extreme polarities. It is these "in-between tendencies" that actually reveal the underlying tensions, laying out how local and global are incorporated, co-opted or blended allowing varying degrees of adjustment. This approximates the reality and better reflects the society we live in.

These tendencies are significant for the following reasons. First, they are visible/noticeable in everyday life and exhibit themselves in the landscape, although the layperson may not explain them in terms of the language that the academics do. Second, one could sense that the dynamics of social change in present day Sri Lanka is acquainted with these tendencies. They are implicated upon changing class identities and disparities - more generally creating new frameworks of reference for social change (Hettige, 1998). Third, on theoretical grounds, it clearly shows how the local culture becomes decisive in negotiating between local and global relations, demonstrating that culture is not a lesser reality than the economic in the wider process of globalization.

Here, it must be emphasized that global-local relations, as they unfold in Sri Lanka, do not add up to or cannot be generalized into objectively identifiable patterns or classifications that social scientists are familiar with (see Dicken et al, 1997: 161 for a similar view). Therefore, a different methodology has been presented focusing on the "most obvious" and trying to unlearn from them. The four examples, to be considered here as "sites of interaction" exhibit the complexity and subtlety in the relations between local and global and their implications. Each presents a different facet of this relationship. Some of the examples that are selected can be unique and idiosyncratic and no claims towards objectivity; yet, preliminary observations both in Sri Lanka and outside indicate a wider applicability. The discussion therefore, describes and explains these examples freely, to show how the local-global relations occur, rather than packing them into some general argument. Intuitive inquiry and analysis of newspaper and television advertisements and programs have largely guided the research, together with a series of formal and informal discussions and interviews.
"McDonalankanization"10 : Global spaces, in the minds of an average Sri Lankan, are places that are ideologically distant although spatially closer (being located in the country), and also different from local architectural styles. Visual difference in the urban landscape has become a principle of registering globalization. To be global, the architectural style and especially the colors have to be different and windows and doors must be modern in both shape and material, and the entire edifice has to be, 'visibly striking in the eyes of the onlookers'. Thus, Pizza Huts in red, McDonalds in yellow and computer shops and internet cafes in purple and blue, super markets and shopping malls in red, orange and white, abiding by this principle of visible difference, standing out in Colombo and other cities are seen as symbolic as well as physical evidence of globalization.

As we know, the McDonald fast food chain prides itself on producing exactly the same standardized products everywhere in the world regardless of geographical location. Ritzer (1993) sees McDonald's fast food restaurant as having a revolutionizing effect on the American society and ultimately the world and illustrates it as a general process that affects "education, work, travel, leisure-time activities, dieting, politics, the family and virtually every sector of the society". In Sri Lanka, McDonalds physically resembles most other McDonalds in the world with similar interior and exterior design, including a "McDonaldland" for the kids. McDonalds now have two outlets in Colombo. In addition to McDonalds, there are about five Pizza Huts and several KFC outlets. KFC prides itself on being the first restaurant to move out of Colombo. ${ }^{11}$

Although these global spaces maintain universal standards, there are qualitative differences in their functioning, which indicate certain deviations from the universal model. In the United States, McDonalds, Pizza Huts and KFCs are certainly not 'status' places. People rush to McDonalds to achieve maximum economic/time efficiency in fulfilling hunger. However, in Sri Lanka these are designed and thought of as places of social status. Firstly, the simple reason is that the cost of food in these restaurants can be borne only by a particular class - that is the 'globals' in Sri Lanka. Secondly, the employees in these fast food places are relatively well educated, conversant in the English language, socially sophisticated and some of them trained in English speaking countries before they start work in these places. In the local context, jobs such as waiters and cleaners (involves sweeping, mopping etc) are denigrated as menial, belonging to the not-so-educated, non- English 
speaking lower strata and are conventionally held by men. To do the same job in a global space is different and it does not carry the same stigma. (Implication: "one is not a 'waiter' but an employee at McDonalds or KFCat global spaces). Thirdly, most customers are English speaking and thus create an environment of exclusivity. Fourthly, these places are kept unbelievably clean by Sri Lankan or even American standards. The global food, visual difference and extraordinary cleanliness, employee profile, and the exorbitant price tags together have assigned these places a higher status and unique affiliation with the globals in Sri Lanka.

However, from a point of view of long-term sustainability, these restaurants cannot distance the non-globals or the locals in the small market in Sri Lanka. Therefore, they have begun to supplement the universal menu in order to entice the local palate; pizza is diversified with local vegetables and chicken (with devilled chicken, spicy veggi and shrimp) while McDonalds offer "McRice" for a relatively low cost. KFC has also introduced, "biriyani"- a popular rice dish and "kottu"-shredded pancake to go with fried chicken. As a manager of McDonalds points out, it is "a little bit of globalization through the hamburgers, seasoned by Lankanization and a sound American work ethic for our employees." 12 Although this attempt to camouflage the "foreignness" embedded within global ventures is a purely market strategy; culturally, it prevents 'alienation of the locals' in global spaces. Introduction of rice is not only a market, but also a cultural strategy. KFC displayed large size advertisements of this rice dish in front of its outlet in Kandy, indicating its relatively low price. For the people passing by, who would otherwise not have gone there, these advertisements of 'biriyani' became an avenue to explore the global in the middle of Kandy -less than two kilometers from the Temple of the Tooth, the most sacred religious-cultural center of the island. ${ }^{13}$

Localizing of the global is not limited to the spatial boundaries of these restaurants, but extends well beyond. These global fast food places have begun to influence the food habits of Sri Lankans, initiating new consumer patterns and behaviors. 'Fast food and eating out' is a new concept in Sri Lankan culture. ${ }^{14}$ Two changes can be observed related to this. Firstly, in most urban areas, localized versions of pizza and hamburgers are produced at relatively low costs to those who cannot afford "original pizza and hamburgers" from global places. In fact, a website cynically coined a term "Mc malu paan"the literal meaning of this is "Mc fish bread". Secondly, local food is prepared in a "quick and easy to take out" manner. Mobile night eating places which offer such food are very popular in urban areas. This should be taken as an economically positive spill effect, as it opens new employment opportunities. Thus, local alternatives to global spaces are being reinvented by these micro enterprises as local economies created through the multiplier effects of globalization.

The other side of the story is that Sri Lanka is well connected through television and media and these new food places are well advertised. ${ }^{15}$ Thus, whether one likes it or not, considered important or not, their impact on changing the food culture in Sri Lanka is diffused. ${ }^{16}$ Short (2001) superficially argues that, "drinking Coca Cola does not make a Russian to think like an American, any more than eating sushi makes the British more like the Japanese." It is not a simple issue of whether eating a hamburger inside a McDonalds will make a Sri Lankan think like an American or not, but its impact extends beyond and relates to larger questions of cultural identity and recognition in society. In fact, Bourdieu (1993) points out that "taste classifies, and it classifies the classifier" and argues that "such distinctions may not create or cause all fresh class divisions as such, but they certainly legitimize social differences". Such is the difference created by global and local pizzas and hamburgers as inculcated through the introduction of McDonalds and Pizza Huts in Sri Lanka.

Ayurveda massage parlors: Ayurveda is an indigenous, nature-based health system practiced in villages and propagated through familial relations. ${ }^{17}$ This system was maintained on reciprocation between the traditional doctor and the patient, with no monetary transaction involved. Usually, a patient would show gratitude by prostrating himself/herself before the doctor with a sheaf of betel leaves or by offering later some gifts which may or may not reflect the exact value of the services. This practice was largely prevalent before the introduction of western medicine, but even after that it did not disappear completely, but remains in the villages to this day.

This system is embedded in complex social relations, imbuing social bonding with a cultural significance giving or helping to find a medicinal herb is considered a meritorious act among the villagers. Indigenous knowledge of these medicines and their whereabouts is considered an asset. The medicine is prepared solely from herbs and plants - a highly specialized, time-consuming activity. As it was a system which relies on nature for its resources, it was imbued with deep environmental values and ethics. This system treats each patient as unique, instead of adhering to a 'one formula for all' as in the allopathic tradition. Even now, this system is held in 
high esteem for snake bites and various forms of arthritis and a few traditional doctors who specialize in them are well known in the country.

National governments recognizing this traditional indigenous medicinal system and its popularity among the people, began to promote it by establishing ayurveda clinics run by state paid doctors. ${ }^{18}$ This move effected certain changes, especially in the preparation of medicine in a more ready-to use manner and in addition, a nominal fee was charged from the patients. The motive behind this state patronage was to sustain this traditional health system for the benefit and welfare of the people. Although this did not change the system dramatically, globalization did affect significant transformations.

Interest in and demand for the 'exotic and indigenous' created by globalization has transformed this traditional health system into a modern economic enterprise, catering largely to the foreign tourists. Now, there are Ayurveda parlors and resorts which have completely modernized the Ayurveda procedures and extend it to massage and relaxation services. Almost all the big tourist hotels now have Ayurveda health resorts as part of their service package. These hotels basically offer Ayurveda more for massage and relaxation than for treatment for diseases, with a very high price tag. ${ }^{19}$ Even some local small-scale companies revered for promoting and preserving this health system have now entered into the "globalizing" phase through establishing their own Ayurveda health resorts for tourists.

As one can see from the internet, Ayurveda no longer belongs to the rural society in Sri Lanka; it belongs to the globals. Although some traditional doctors still treat the patients in their own villages, the effects of globalizing competition is gradually felt by them as well. University trained Ayurveda doctors are opening 'private consulting clinics' in the cities in the style of the western medical clinics and some of them now seek employment in the hotels rather than in government Ayurveda clinics. ${ }^{20}$ These doctors who have practical knowledge of the Ayurveda system are now attracted to the global spaces.

Globalization has created a market demand for this health system which was once limited to the barter system found in rural areas. Today, traditional herbs and plants are bought; employees involved in preparation and treatment procedures are paid; services are well advertised: thus completely capitalizing the concept and commodifying the practice. The system once steeped in cultural relations of reciprocity and mutual bonding in the villages has become a pure business venture, devoid of such relations, in the tourist health resorts. Even the traditional doctors remaining in rural areas now charge higher fees to treat the patients as a result of the demand created by globalization. In this context, to speculate an extreme possibility, locals may not be able to access their own traditional health system in the future, as they used to do, as it is becoming monetarized as well as too modernized and globalized.

The journey of local handicrafts to global space: An assortment of traditional handicrafts has been produced in the rural villages from ancient times. This industry is incredibly local and carried on largely by using family labor with art and skills inherited from earlier generations. It is carried on in their own homes either as the main economic activity or a source of additional income. These products are traditionally identified with certain specific regions and villages in the country and as a result, they carry the name of the region as their brand name. Although the post-independence governments are blamed for allowing these small industries to deteriorate, the liberal policy has, in fact, opened new markets for such products as a response to the resurgent interest in local and traditional products as 'exotic items of decoration' among the globals. What I have outlined below as an example, is a journey of local handcrafts unique to a particular area, for example, Dumbara to a global shop in Colombo as an example.

The most famous area for traditional crafts in Sri Lanka is known as "Dumbara", "Dumbarawase" is the Dumbara Vally located in the mid hill country. They produce wall hangings, bags, carpets and mats, cushions, etc. Dumbara ware is well known for their unique geometric patterns and their craftsmanship is revered even in the popular folklore. It largely catered to a limited local utilitarian market facilitated by the government and to those who are passing through these areas who could also buy these products from the craftsmen's homes at a much lower price.

"Craw ${ }^{21}$ "is an exclusive shopwhere traditional handicrafts are sold both to the foreign tourists and the globals in Sri Lanka. They purchase "Dumbara" products from the rural hand weavers and sell them at an astonishingly high price. They make certain modifications to these products making them "value-added" to assure quality (seams are $100 \%$ perfectly done; bright colors are introduced, items are attractively displayed, packaged and advertised). This is an air-conditioned, well-decorated shop in the post-modern fashion, situated in an area in Colombo which is the archetype of the globalizing landscape. 
Definitely the 'global' shop benefits most from these local products and even from its traditional brand name. Local products did not carry patent rights and such traditional brand names were considered, not as market rights but as public properties of the local culture. Now, they are appropriated by the global and enhanced to match the expected quality of the urban high-end market. What is ironical here is that the local producers are not benefited by the production dynamics imposed on their own products at the global shop. For example, the technology and skills required for value addition is not given to them, thus marginalizing them from the benefits of globalization. ${ }^{22}$ As a result, they remain as rural poor primary producers, while their products may achieve global status. As in many other cases, the local is making a simple obligatory journey to the global in the form of a transaction- no enhancement for themselves - as can be well observed from the visible poverty of places of production.

Consumer cross shifts: The last example refers to a particular set of consumer cum cultural behavior, that has been identified as indicative of a cross shift from the global to the local and vice versa ${ }^{23}$. To elaborate this with a simple example, certain consumer items and cultural forms that were considered and even redeemed previously as local and traditional are now incorporated into the global while being gradually abandoned by the locals. Equally, there is a rapid transfer of global items and cultural forms into the local. None of these, as mentioned earlier add up to any identifiable pattern. Table 1, summarises readily noticeable shifts - both cultural and economic.

This cross shift constitutes two trends. Firstly, the global (previously 'modern') continues as the ideal of social change for the locals and is accelerated by globalizing tendencies by which their material life is influenced. The notion of "globalization as doxa" helps us to understand this situation faced by the locals. Shirato and Webb (2003) explain, "doxa as the effect of something coming to seem true and necessary, so that people will accept that as 'just the way things are'". Secondly, the attraction towards the local by the globals is relatively new and was initiated by globalization. Most importantly, this shift is not necessitated by material needs, but by ideological 'wants' to justify their 'local identity', or to put it in a spatial metaphor - to overcome the distance to the localwhich itself is venerated within the popular discourse of globalization as hybridity. Globals adopt the 'local' by choice, not out of necessity. ${ }^{24}$ Most interestingly, these cross shifts are sustained not in pure global or local form, but as in-between positions allowing their easy adoption.
For example, traditional home remedies are prepared as capsules and instant drinks to suit the globals, while processed food and certain essential cosmetic items are produced in 'one serving sachets' at lower prices affordable by the locals, ${ }^{25}$ They are extensively promoted by advertisements (both in the newspapers and the television) that evoke new local cultural traditions.

It is important to note that this cross shift has initiated both negative and positive impacts. For example, the process definitely provides a space for the local products to enter into the global market (hence an enhancement and opportunity), although the question of who receives the benefits or whether the local producers are justifiably compensated in the capitalist market remain as issues to be probed further. There is also the increased potential for greater exploitation of the local resources, practices and customs by the market without any due procedure or consideration (question of patent rights in the case of herbs and medicinal plants as an example - hence, exploitation and misappropriation). Nevertheless, the shift from the local to global has created a marketdriven resurgent interest in traditional cultural forms and elements.

\section{IMPLICATIONS AND CONCLUSIONS}

Overall, these examples clearly demonstrate two aspects that are important in examining the relationship between the global and the local. First, they reveal that not only is the local being globalized, but also, contrary to the conventional view, the global is also being localized (also see Amin and Thrift, 1997 for a similar view). Further, it is also not a situation where one is completely swamped by the other, but they intermingle into interrelated tendencies absorbing elements of each other (universal McDonald hamburgers to 'alternative hamburgers' and rural Ayurveda practice to massage parlors). Secondly, the global-local relationship is not a simple matter of economic logic, but of a cultural logic too - a fact that is rather neglected in the studies of globalization within geography. In each of the examples, while the economic reasoning and virtues of bringing the global and local together are crystal clear, it is the cultural logic that has made this engagement possible and somewhat 'natural'. As Sayer (1997) argues, "culture can be instrumentalized to serve economic ends, but this can be accepted precisely because of the value of those cultural elements. Culture is significant in everyday life, because it is what gives people and the places they live in distinctiveness and a measure of identity (Friedmann, 1994). In view of this, it is paramount that globalization comes in contact with the cultural realm. 
In the Sri Lankan case, it is clear that adventuring into the local culture becomes instrumental for the global ventures and practices to achieve local authenticity, which is essential in ensuring legitimacy in both a cultural and economic sense - to attract both the minds and the wallets (although not necessarily in this order!). Even in the process of 'globalizing the local', it is the 'culturally unique' that has caught the attention (e.g. ayurveda and Dumbara handicraft). However, in the drive to achieve local authenticity, certain cultural forms, practices and values are being commodified in the capitalist market.

As a whole, the interplay of the global and the local, together with its manipulation of local culture, has produced two transformative tendencies/ sensitive issues in the context of globalization in Sri Lanka. First, there is a tendency of displacing local culture. This displacement occurs simultaneously, but in two specific ways. On one hand, certain cultural elements and practices (e.g. Ayurveda and Dumbara products) are decontextualized and repackaged (thus displaced from their localness) to suit the interests of the globals. As all of us are aware, modernization rejected local culture as traditional and upheld the 'western' as the ideal. The dynamic global market has changed this, making local culture available within the global space rather than eliminating it. Appropriation of local culture by the globals has thus become a form of "stylization of life' 26 for aesthetic and symbolic pleasures. On the other hand, the locals are distancing themselves from certain cultural practices and elements for material reasons (thus displaced from their localness). Significant changes are occurring in material life and social relations in the villages. For example, serving rice on banana or lotus leaves in a "wattiya" (basket) used to be a specific practice tied to paddy farming. It has its own cultural dynamics from collecting material to weaving the "wattiya" by women during their leisure time to the feasts held during farming. Influenced by the "plastic culture" of globalization (plastic implements are very cheap!), villagers now use plastic plates and wrappers while lotus/banana leaves make their journey to the restaurants in supermarkets and large tourist hotels. Given this scenario, the possibility exists that certain cultural forms and practices will be dislocated from their material and particular social relations within which they were nurtured and they may find only a symbolic niche in global spaces. ${ }^{27}$

The second issue is moral-political. While it is true that the two - local and global may traverse shaping each other, the global is causally powerful (as the hegemonic) thus holding the veto power of manipulation. The globals have the power to acquire 'culturally what is local', without having to change their material relations. To put it differently, for the rural people appropriating the "global" becomes a matter of material necessity and hope, while for the globals, appropriating local is simply a matter of choice constantly and easily within their reach. Not only can globals reach what is global at their doorstep- such as pizza and hamburgers- in an appealing way, they can now enjoy the 'distant local' which was once rejected under the modernization ideology. For the locals, it is a challenge to acquire the icons of globalization to ensure recognition in society while fighting for their material existence. This differential impact evokes a moral and political question and pinpoints the inherently undemocratic nature of globalization. Both these issues together- displacing of local culture and the differential impact on the locals and globals, emerges as a critical reference point of social change in Sri Lanka in the context of globalization. ${ }^{28}$

These changes occurring in places such as Sri Lanka compel geographers not only to inquire into specific geographies as much as possible, but also to revise conceptual lenses in comprehending globalization in different places. ${ }^{29}$ Pizza Huts, McDonalds and Ayurveda parlors are not simply icons (as one might see in a bird's eye view) of globalization, but "sites of interaction that are socially produced", in which different scales constantly negotiate with each other, extending their impacts beyond. Or as Dicken, Peck and Tickell (1997) point out, "one can study globalization without succumbing to the excesses of 'globaloney'" .

In this context, firstly, it is clear that more empirical analysis of globalization is needed instead of circumventing the theoretical arguments - as the title itself indicates, "globalization from within." Secondly, there is a need to move away from the conventional scale analysis done for the sake of empirical justification and to focus on specific cases, softening boundaries of the rigid sub-discipline (e.g. economic and cultural geography) and the conceptual barriers (e.g. the 'economic' and the 'cultural') contained within them. Or as Rosenau (2003) points out it is critical 'to locate distant proximities at the center of our perspectives'. Thus, it could be concluded that conceptualizing the relatioship between "global" and "local" as a dialectical yet contingent process is necessary, because the exact articulations of "global" and "local" depend on specific places and not only on their economic but also cultural contexts. Here the objective must be, not to make generalizations or write postscripts to globalization, but to make sense of or to reflect upon the dynamics and specificities of human experience entailed within it. ${ }^{30}$ 
Table 1: Cross-Shifts identified between the local and the global

\begin{tabular}{|c|c|}
\hline From global to local & From local to global \\
\hline $\begin{array}{l}\text { Panadol, Disprin, Asprin, Piriton in the local shops } \\
\text { (These are accepted as drugs that gives fast relief.) } \\
\text { They are taking their place of traditional "Ath beheth" } \\
\text { (hand made medicines using herbs such as garlic, } \\
\text { corriander, gotukola etc. While garlic and coriander } \\
\text { mixture is used for colds, water of boiled gotukola } \\
\text { roots is used for worm treatment) }\end{array}$ & $\begin{array}{l}\text { Garlic and Gotukola (a very nutritious green leaf } \\
\text { plant) pills, Tripala capsules in urban supermarkets. } \\
\text { (Here,garlic, karawila and gotukola are all made into } \\
\text { easy-to-use tablets. Tripala is a capsule made out } \\
\text { of three prominent traditional herbs for treatment of } \\
\text { stomach aches and worm treatment. }\end{array}$ \\
\hline $\begin{array}{l}\text { "Keells" appears as a prominent food item in rural } \\
\text { areas now In the villages, canned Mackerel which } \\
\text { is popularly known as "salmon" in Sri Lanka has } \\
\text { been an item of luxury with which the visitors are } \\
\text { often treated. Now, this is being gradually replaced } \\
\text { with what is identified as, "Keells". Keells is a local } \\
\text { company that produces most of the processed meat } \\
\text { items such as sausages and meatballs. These foods } \\
\text { have replaced the luxury value of the "salmon" } \\
\text { and people identify any processed meat as "Keells" } \\
\text { regardless of the producing company .The impact } \\
\text { of theis is such, that the national television ran a } \\
\text { commercial by modifying a lullaby that was used } \\
\text { while feeding the small children, changing the word } \\
\text { "rice" in the lullaby to "Keells" implying meatballs } \\
\text { and sausages. }\end{array}$ & $\begin{array}{l}\text { Organic food and exotic traditional food items have } \\
\text { become prominent in urban markets. All varieties } \\
\text { of exotic and rare-to-find traditional greens and } \\
\text { vegetables can now be found in the urban high } \\
\text { market, whereas rural people are not too keen about } \\
\text { them. This resurgent interest in the urban market } \\
\text { has led to a propagation of these varieties by local } \\
\text { producers. } \\
\text { Kolakenda (green leaf porridge) now comes in } \\
\text { instant form in a sachet, although traditionally its } \\
\text { preparation was time-consuming, labor intensive and } \\
\text { needed equipment such as a mortar and a pestle. But } \\
\text { now electric blenders and food processors have taken } \\
\text { that place in urban households. }\end{array}$ \\
\hline $\begin{array}{l}\text { Increasingly the locals use plastic plates and lunch } \\
\text { papers in their agricultural functions instead of } \\
\text { traditional banana and lotus leaves on a wattiya (hand } \\
\text { woven cane container) for eating. }\end{array}$ & $\begin{array}{l}\text { Banana and lotus leaves in wattiya are used to serve } \\
\text { food in restaurants in urban supermarkets and certain } \\
\text { tourist hotels. }\end{array}$ \\
\hline $\begin{array}{l}\text { Rap music (the younger generation prefers local } \\
\text { versions of loud and high-pitch music of Michael } \\
\text { Jackson etc or Sri Lankan equivalents of them) }\end{array}$ & $\begin{array}{l}\text { Folklore being given new tunes and hybrid dancing } \\
\text { which is a blend of traditional, Indian and western. }\end{array}$ \\
\hline $\begin{array}{l}\text { Increasingly western dress for both formal and } \\
\text { informal occasions although women still continue to } \\
\text { wear the traditional dress. }\end{array}$ & $\begin{array}{l}\text { Wearing the "national dress" known as "sarong" in } \\
\text { modified form (e.g. traditional dress is pure white, but } \\
\text { now they wear in bright colors) is now high fashion } \\
\text { among the globals. }\end{array}$ \\
\hline
\end{tabular}




\section{Notes}

1 This is not to devalue the merits or the need of the globalist approach in understanding broader processes of globalization, but to highlight the fact that we need to unravel the dynamics of specific places.

2 I interpret it here that the key word is context and not global.

3 Hulsemeyer ed. (2003) attempts a similar analysis. But the different scales have merely become instruments of analytical convenience to substantiate the argument that globalization involves both convergence and divergence.

4 See Rosenau's classification of locals -insular, resistant, exclusionary and affirmative (2003:80-85). These variations reflect the relative distance from and to, local and global. I suppose the globals can also be categorized in the same way.

5 Here, it should be noted that Robertson's work on globalization is very theoretical and analyzed in relation to social theory. But Robertson also pays attention to its 'cultural turn'.

6 See Kofman and Youngs (1996) for a critique of the universal discourse of globalization.

7 See Sayer (1997). Sayer's idea on culture and economy are enlightening for the discussion on globalization although they were not integrated into the debate.

8 There is a rapid expansion of private institutions offering computer education in cities and gradually spreading to rural areas.

9 The government has effected educational reforms by introducing the English medium from grade six onwards and computer education in the national schools.

${ }^{10} \mathrm{I}$ am using "McDonalankanization by combining 'McDonalds' and 'Lankanization' in a generic sense to refer to the introduction of fast food by McDonalds, Pizza Hut and KFC in Sri Lanka and their local adaptation. Also see Ritzer's (1993) on McDonaldization.

${ }_{11}$ McDonalds started its first outlet in Colombo in 1998 as the 114th country of its expansion whereas Pizza Hut began as early as 1993 and now have about five outlets in Colombo itself. All these now have online ordering facilities.

12 See Careem, Zanita "Special Feature on Leisure", The Island, 03/24/2002

${ }^{13}$ Rice is the staple food in Sri Lanka. It is also the "culturally staple food", as people believe that if rice is not eaten for three consecutive meals, one is actually starving.

${ }^{14}$ Almost everybody takes a packet of rice and curry for their lunch, while breakfast and dinner are usually taken at home.
15 Pizza Hut runs an attractive advertisement on delivering pizza in the vicinity of Colombo.

${ }^{16}$ See Row 2 of table 1 for the impact of Keels.

17 The term has its origin in Sanskrit - "Ayuh" (life) and veda (knowledge/science). While this is also practiced in India, Sri Lankan history records with evidence that ancient kings patronized this system as early as A. D. 398.

18 There is a University which trains the doctors for this health system.

19 Certain therapy packages such as "pancha-karma" can cost $\$ 420$ per person per week with an additional week being $\$ 665$. These packages are well publicized through the internet and most publicity is given in Germany. Some hotels have also extended these packages to slimming and beauty care programs.

${ }^{20}$ Ayurveda doctors were socially looked down upon as traditional and unsophisticated before this change.

21 This is not the real name of the shop.

22 Amin and Thrift's (1997) discussion on the need to improve 'interactive institutional networks' to facilitate 'positive engagement within the global economy' is quite relevant here.

23 As a non-native English speaker, I thought that "cross shift" is the best term as it involves crossing boundaries as well as shifting of one's own space.

${ }^{24}$ The principle here is that the "globals" become more powerful in the local context when they ally with local traditional values and practices as it gives legitimacy for them to speak on national issues.

${ }^{25}$ Rural boutiques are flooded with these "one serving packets" and they are quite popular with the customers. For example, Keels company produces "meat balls packet -white or red curry taste" for a four member family at an apparently low cost for the item. Various hair products (esp. shampoos) are produced in small packets "single use and throw style". Rural customers can afford to buy them as the item price is very low although the unit price can be higher.

26 The term 'stylization of culture' is taken from Sayer, (2000) in reference to Featherstone, 1994.

${ }^{27}$ In fact, Nijman points out that "globalization does not erase local cultures, but it does undermine their original form." (1999).

${ }^{28}$ Hettige (1998) argues that integration into the world economy has led to a realignment of class and ideological forces, especially in terms of their location in the socio-cultural space which spreads between the polarities of universalism and particularism.

${ }^{29}$ One of the problems that I observe in Human Geography is that important issues are often argued out in separate groups in particular time periods (i.e. place debate, economy-culture debate), but they are not adequately reflected in the studies within Geography. 
${ }^{30}$ Infact, a non-geographer warns us, that "the variability of localizing processes also serves as a useful reminder that the dangers of generalizing about the impact of globalization..... This is not to downplay the powerful ways in which globalization is generating commonalities around the world" (Rosenau, 2003).

\section{References}

1. Agnew, J. \& Grant, R., 1997. Falling out of the World Economy? Theorizing 'Africa' in World Trade. In: J. Wills \& R. Lee, eds. Geographies of Economies. London: Arnold.

2. Allen, J., 1995. Crossing Borders: Footloose Multinationals. In: J. Allen \& C. Hamnett eds., $A$ Shrinking World. Oxford: Oxford University Press.

3. Allen, J \& Massey, D. eds., 1995. Geographical Worlds. Oxford: Oxford University Press.

4. Amin, A. \& Thrift, N. eds., 1994. Globalization, Institutions and Regional Development in Europe. Oxford: Oxford University Press.

5. Amin, A. \& Thrift, N., 1997. Globalization, Socioeconomics, Territoriality. In: J. Wills \& R. Lee, eds. Geographies of Economies. London: Arnold.

6. Appadurai, A., 1990. Disjuncture and Differences in the Global Cultural Economy. In: M. Featherstone, ed. Global Culture: Nationalism, Globalization and Modernity. London: SAGE publications.

7. Appadurai, A., 1996. Modernity at large: Cultural Dimensions of Globalization. Minneapolis, M.N.: University of Minnesota Press.

8. Barrett, H. R., Ilbery, B.W., Browne, A.W. \& Binns, T., 1999. Globalization and the Changing Networks of Food Supply: the Importation of Fresh Horticultural Produce from Kenya to UK. Transactions of the Institute of British Geographers, 24, pp. 74-159.

9. Bourdieu, P., 1993. The Field of Cultural Production: Essays on Art and Literature. R. Johnson, ed. New York: Columbia University Press, p. 18.

10. Cerny, P. G., 1997. Paradoxes of the Competition State: the Dynamics of Political Globalization. Government and Opposition, 32, pp. 251-74.
11. Cerny, P. G., 2003. Globalization and other Stories: Paradigmatic Selection in International Politics. In: A. Hulsemeyer, ed. Globalization in the twenty-first century. New York: Palgrave Macmillan.

12. Cox, K. R., 1997. Globalization and Worker's Struggle in the late Twentieth Century. In: J. Wills \& R. Lee, eds. Geographies of Economies. London: Arnold.

13. Dicken, P., 1998. Global shift. 3rd ed. London: Paul Chapman.

14. Dicken, P., Peck, J. \& Tickell, A., 1997. Unpacking the Global. In: J. Wills and R. Lee, eds. Geographies of Economies. London: Arnold, pp. 160- 65.

15. Dodds, K., 1999. Political Geography I: the globalization of world politics. Progress in Human Geography, 22, pp. 595-606.

16. Ettlinger, N., 1999. Local Trajectories in the Global Economy. Progress in Human Geography, 23(3), pp. 335-57.

17. Fagan, R., 1997. Local Food/Global Food: Globalization and Restructuring. In: J. Wills \& R. Lee, eds. Geographies of Economies. London: Arnold.

18. Featherstone, M., 1990. Global Culture: an Introduction. In: M. Featherstone, ed. Global Culture: Nationalism, Globalization and Modernity. London: SAGE publications.

19. Friedman, J., 1994. Cultural Identity and Global Process. London: Sage.

20. Hannerz, U., 1990. Cosmopolitans and Locals in the World Culture. In: M. Featherstone, ed. Global Culture: Nationalism, Globalization and Modernity. London: SAGE publications.

21. Harvey, D., 1989. The Condition of Postmodernity: an Inquiry into the Origins of Cultural Change. Oxford: Blackwell.

22. Herod, A., 1997. Notes on a Spatialized Labor Politics: Scale and the Political Geography of Dual Unionism in the U.S. Longshore Industry. In: J. Wills and R. Lee, eds. Geographies of Economies. London: Arnold. 
23. Hettige, S.T., 1998. Pseudo-modernization and the Formation of Youth Identities in Sri Lanka. In: S.T. Hettige, ed. Globalization, Social Change and Youth. Colombo: German Cultural Institute.

24. Hulsemeter, A. ed., 2003. Globalization in the Twenty-first Century Convergence or Divergence. New York: Palgrave Macmillan.

25. Kelly, P. F., 1999. The Geographies and Politics of Globalization. Progress in Human Geography, 23, pp.379-400.

26. Kofman, E. \& Youngs, G., eds., 1996. Globalization: Theory and Practice. London:Pinter.

27. Kortan, D. C., 1995. When Corporations Rule the World. New York: Kumarian Press.

28. Leyshon, A., 1997. True Stories? Global Nightmares, Global Dreams, and Writing Globalization. In: J. Wills \& R. Lee, eds. Geographies of Economies. London: Arnold.

29. Leyshon, A. \& Thrift, N., 1993. The Restructuring of the UK Financial Services Industry in the 1990s: a Reversal of Fortune. Regional Studies, 9, pp. 22341.

30. Mandal, S. K., 2000. Reconsidering cultural globalization: the English language in Malaysia. Third World Quarterly, 21 (6), pp. 1012-2000.

31. Mittelman, J. H. \& Othman, N. eds., 2001. Capturing Globalization. New York: Routledge, p. 12.

32. Nijman, J., 1999. Cultural Globalization and the Identity of Place: the Reconstruction of Amsterdam. Ecumene, 2, pp.146-64.

33. Ohmae, K., 1990. Borderless World: Power and Strategy in the Interlinked Economy. London: Harper Collins.

34. O'riordan, T. ed., 2001. Globalism, Localism and Identity: Fresh Perspectives on the Transition to Sustainability. London: Earthscan, p. 34.

35. Osman, S., 2001. Globalization and Democratization: The Response of the Indigenous Peoples of Sarawak. In: J. H. Mittelman \& N. Othman, eds. Capturing globalization. New York: Routledge.
36. Park, B., 2003. Politics of Scale and the Globalization of the South Korean Automobile Industry. Economic Geography, 79, pp.173-94.

37. Peck, J. \& Tickell, A., 1994. Jungle Law Breaks out: Neo-liberalism and Global-Local Disorder. Area, 26, pp. 317-26.

38. Peck, J. \& Tickell, A., 1992. Business goes Local: Dissecting the Business Agenda in Manchester. International Journal of Urban and Regional Research, 19, pp.55-78.

39. Roberts, S., 1992. The World is Whose Oyster? The Geopolitics of Representing Globalization, AGG National Meeting, San Diego.

40. Robertson, R., 1992. Globalization, Social Theory and Global Culture. London: SAGE Publications.

41. Robertson, R., 2003. The Three Waves of Globalization: a History of a Developing a Global Consciousness. London: Zed Books.

42. Ritzer, G., 1993. The McDonaldization of Society. Thousand Oaks, CA: Pine Forge Press, p.1.

43. Rosenau, J. N., 2003. Distant Proximities: Dynamics beyond Globalization. Princeton: Princeton University Press, pp 3-5.

44. Sayer, A., 1997. The Dialectic of Culture and Economy. In: J. Wills \& R. Lee, eds. Geographies of Economies. London: Arnold.

45. Sayer, A., 2000. Critical and Uncritical Cultural Turns. In: I. Cook, D. Couch, S. Naylor \& J.R. Ryan, eds. Cultural Turns/Deographical Turns. New York: Prentice Hall, p.25.

46. Schirato, T. \& Webb, J., 2003. Understanding Globalization. London: SAGE Publications, p.131.

47. Schaeffer, R. K., 2003. Understanding Globalization: the Social Consequences of Political, Economic, and Environmental Change. 2nd ed. New York: Rowman \& Littlefield Publishers, INC.

48. Scholte, J. A., 2000. Globalization: a Critical Introduction. New York: St. Martin's Press Inc. 
49. Scott, A. ed., 1997. The Limits of Globalization: Cases and Arguments. London and New York: Routledge.

50. Short, J. R., 2001. Global Dimensions: Space, place and the Contemporary World. London: Reaktion Books.

51. Skelton, T., 1996. Globalization, Culture and Land. In: E. Kofman \& G. Youngs, eds. Globalization: Theory and Practice. London: Pinter.

52. Sklair, L., 2002. Captialist Globalization in China. In: Globalization, capitalism and its alternatives. 3rd ed. Oxford: Oxford University Press.

53. Smith, A.D., 1990. Towards Global Culture: an Introduction. In: M. Featherstone, ed. Global Culture: Nationalism, Globalization and Modernity. London: SAGE publications.

54. Street, J., 1997. 'Across the Universe': The Limits of Global Popular Culture. In: A. Scott, ed. The limits of globalization: cases and argument. London: Routledge.
55. Swyngedouw, E., 1992. The Mammon Quest. 'Glocalization,' Interspatial Competition and the Monetary Order: the Construction of Scales. In: M. Dunford and G. Kafkalas, eds. Cities and Regions in the New Europe. London: Belhaven Press.

56. Swyngedouw, E., 1997. Excluding the Other: the Production of Scale and Scaled Politics. In: J. Wills \& R. Lee, eds. Geographies of Economies. London: Arnold.

57. Taylor, M. J. \& Thrift, N. J. eds., 1986. Multinationals and the Restructuring of the World Economy. London: Croom Helm.

58. Voisey, H. \& O'riordan, T., 2001. Globalization and localization. In: T. O'riordan, ed. Globalism, Localism and Identity: Fresh Perspectives on the Transition to Sustainability. London: Earthscan, p. 37.

59. Waters, M., 1995. Globalization. London: Routledge.

60. Yeoh, B. S. A., 1999. Global / Lobalizing Cities. Progress in Human Geography, 23, pp. 607- 16. 